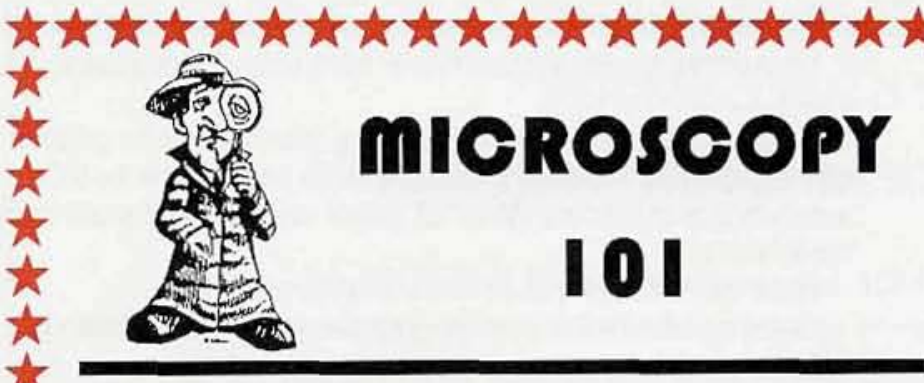

We appreciate the response to this publication feature - and welcome all contributions. Contributions may be sent to Phil Oshel, our Technical Editor at:

$$
\begin{aligned}
& \text { Mr. Phil Oshel } \\
& \text { Station A } \\
& \text { PO Box } 5037 \\
& \text { Champaign IL 61825-5037 }
\end{aligned}
$$

or by eMail: poshel@hotmail.com

Please note new eMail address

\section{Three Quick Hints for Working with LR White Resin}

The following "hints" are based on my experience using a Ted Pella 3450 microwave tissue processor:

1) Vent your microwave tissue processor to the outside. We have noticed that if samples of LR White are not covered during polymerization, the media does seem to sublimate, then recondenses and polymerizes on all surfaces. This is our experience during the polymerization of LR White in a nitrogen rich chamber heated to $60^{\circ} \mathrm{C}$. Using the microwave, consider submersing BEEM capsules, sealed with Parafilm under the cap, in water. This will insure that LR white fumes do not enter the microwave during polymerization. Use the temperature limiting probe to limit the temperature of the water to $70^{\circ} \mathrm{C}$ and polymerize for 60 minutes, or set to $80^{\circ} \mathrm{C}$ and polymerize for 45 minutes. A $500 \mathrm{~mL}$ beaker with recirculated water at 10 to $20^{\circ} \mathrm{C}$ should also be included in the microwave during polymerization.

2) We use formvar coated Nickel grids. We prefer slot grids, but use whatever you prefer. You may want to use uncoated nickel grids if you wish to label both sides for a double labeling protocol.

3) A progressively lower temperature scheme is best for alcohol dehydrations:

Start with $30 \%$ EtOH at $0^{\circ} \mathrm{C}$ for 10 minutes, then

Lower to $-10^{\circ} \mathrm{C}$ for another 10 minutes

Add $50 \%$ EtOH at $10^{\circ} \mathrm{C}$, then

Lower to $-20^{\circ} \mathrm{C}$

All subsequent steps to $1: 390 \%$ EtOH:LRW should be at $-20^{\circ} \mathrm{C}$

We also leave the samples overnight in $100 \%$ LR White at $-20^{\circ} \mathrm{C}$, then raise the temperature to ambient for another hour or so prior to thermal polymerization. We might be too careful. Work could be done in the cold room (brrmr!) to obtain $-20^{\circ} \mathrm{C}$.

Doug Keene, Shriners Hospital for Children, Portland, Oregon

\section{An Easy Method For Filling Vacuum Desiccators With Clean, Dry Nitrogen.}

People seem to like to store various objects (specimens, pole pieces, specimen holders, etc.) in plastic vacuum desiccators under vacuum, and there are two problems that can arise when doing so:

1) The desiccator may have a small leak, and over time come back up to atmospheric pressure, thus exposing the objects to ordinary air - the situation that is trying to be avoided.

2) Under the influence of the vacuum, plasticizers may bleed out of the plastic from which the desiccator is made and find their way onto the stored objects.
The second of these problems can, of course, be avoided by using glass desiccators, but the possibility of the first arising would still exist.

Fortunately, both problems can be minimized quite simply by filling the desiccator to atmospheric pressure with a dry, inert gas, rather than leaving it evacuated. For most purposes, dry nitrogen would be a satisfactory gas to use here, although helium or argon might be preferred for storing some reactive materials. If the gas Is purchased in a high pressure tank, it is necessary to be sure that it is oil-free, otherwise the fill-gas may carry oil vapors onto the stuff you are storing inside the desiccator.. This would defeat the purpose of the whole operation, a matter discussed on page 64 of my book Vacuum Methods in Electron Microscopy

The vapor pressure of water at the temperature of liquid nitrogen is in the realm of $10^{-20} \mathrm{Torr}$, and the vapor pressure of most oils is even lower, so the gas that is constantly boiling off each container of liquid nitrogen is about as clean and dry as any you can get. As described on page 65 of Vac. Meth. in EM, this dry nitrogen can be collected and used to fill vacuum apparatuses rather simply:

1) Fit a one-hole stopper Into the $L N_{2}$ storage flask and connect it to the inlet valve of the vacuum container with noncollapsible, flexible tubing. Ordinary polyethylene tubing works well.

2) Attach a large, collapsible plastic beach ball to a Tee joint in this tubing with a length of soft, surgical-rubber tubing, and make a clean slit in this surgical tubing about $100 \mathrm{~mm}$ long with a sharp razor blade or scalpel. Ordinarily this slit will close tightly enough so that the nitrogen gas evolved from the storage container will be directed into the beach ball; however, if the ball becomes full, the slit will serve as a primitive pressure-release valve by opening slightly and allowing the gas to escape so that there is no danger of over-pressurization.

3) When the inlet valve to the evacuated chamber is opened, the nitrogen will flow into the chamber only under the influence of atmospheric pressure acting on the collapsible beach ball, so there is no danger of exceeding atmospheric pressure in the chamber. An ordinary beach ball will hold enough gas to fill most desiccators several times.

If an oil-sealed rotary vane pump is used to evacuate the desiccator, then some care must be exercised to avoid having oil vapors backstream from the pump into the chamber. To avoid this, it is important not to pump the chamber down below the range of viscous flow (i.e., below about 0.1 Torr - see page 29 of Vac. Meth. in EM). It this is not considered to be a sufficient vacuum to remove as much atmospheric gas as desired, then the container can be filled with the dry gas, pumped out and filled again a couple of times. Each time the container is pumped out some $90 \%$ of the existing gas molecules is removed, so two or three flushings should leave only an insignificant trace of the original atmospheric gases. Alternatively, the problem of the backstreaming of oil during evacuation can be eliminated by using an oil-free rough vacuum pump, such as a carbon vane, diaphragm, or scroll pump. The problem here being that such pumps are not commonly available in most laboratories.

\section{Wilbur C. Bigelow, University of Michigan}

\section{A Note On Fixing And Embedding Vertebrate Eyes}

I have had experience from mice to whales, and a lot in between. I would recommend Davidson's as a fix. It will keep your retina from going for a walk. Secondly, paraplast is a problem for eyes. A higher melting point wax is needed, without all of the fancy extras. I use Peel Away with a melting point of $56^{\circ}$ to $58^{\circ} \mathrm{C}$

The eyes can be processed using another paraffin on the processor, then transferred into Peel Away for the last change in a warming oven for about an hour.

I have processed using both Xylene and Propar, and both worked fine, although you need to adjust the time for Propar.

When I cut, I place my ribbons on to a room temperature distilled water bath, then pick up the sections onto a slide and float them out in a $52^{\circ}$ to $54^{\circ} \mathrm{C}$ water bath.

Place the optic nerve at the label end so it isn't blown out with the heat; it will be evident if the water is too hot, too quickly! I routinely cut at $4 \mu \mathrm{m}$, 